\title{
EDITORIAL
}

\section{Risk assessment in coronary artery surgery}

\section{J R Pepper}

Without risk stratification, surgeons and hospitals treating high risk patients will appear to have the worse results. This is regrettable as it is these very patients who stand to gain most from undergoing surgery

Q uality assurance and league tables are part of the contemporary medical scene. During the 1980s, the revolt of the payers of health care, both private and public, led to the mantra that the cost of treatment must be taken into consideration in decisions about the provision of health care. In cardiac surgery the difference between success and failure is transparent and obvious to all, from the porter to the chief executive. It has come to be accepted that operative or hospital mortality is an indicator of the quality of care. For hospital mortality to remain a valid measure of quality, it must be related to the risk profile of the individual patient. Therefore much effort has been expended on the development of a robust and reliable risk stratification model.

It is inevitable that within the climate of transparency, the availability of results and public accountability will influence decision making. Without risk stratification, surgeons and hospitals treating high risk patients will appear to have worse results than others. This may prejudice referral patterns, affect the allocation of resources, and discourage the treatment of high risk patients. This is undesirable, because it is precisely this group of patients which stand to gain most from operation. ${ }^{1}$ Risk stratification should help to eliminate the bias against high risk patients.

\section{DOES RISK STRATIFICATION WORK?}

Risk assessment serves many masters: the payer to justify expenditure and provide a tool for health policy; the hospital to defend itself in league tables; the surgeon to watch his back; and lastly but most importantly, the patient who has to decide whether or not to entrust his or her life into the hands of strangers. Intuitively, we might expect that the routine feedback of risk adjusted data on local performance in a cardiac surgical unit would heighten awareness and lead to self examination, which in turn would improve quality and outcome. Formal evaluation in North America appears to support this notion. A 10 year review of the Department of Veteran Affairs (VA) and the Society of Thoracic Surgeons (STS) national databases was conducted to appraise their use as quality improvement tools. Both databases showed a significant reduction in the risk adjusted surgical death rate, despite the fact that patients presented with an increased risk factor profile. The ratio of observed to expected deaths decreased from 1.05 to 0.9 for the VA and from 1.5 to 0.9 for the STS. ${ }^{2}$

In this issue of Heart, Petrou and colleagues ${ }^{3}$ have tested five established risk models on the National Adult Cardiac Surgical Database. Bayesian models are attractive from the theoretical viewpoint and are probably more accurate for small subgroups of patients and especially very high risk patients, but they are more complicated to use. It is therefore very helpful to discover as a result of these authors' work that the simple additive version of EuroSCORE works just as well. This appears to be a useful instrument for risk assessment in coronary artery surgery in Europe, including the UK. We should not expect too much from risk assessment at this time. In the UK 30\% of hospitals undertaking cardiac surgery do not have adequate facilities for audit, namely a data manager and a network computer system. It is also important to periodically revisit the chosen risk model. Ivanov and colleagues investigated this point in Toronto at two teaching hospitals. ${ }^{4}$ They found that poorly calibrated risk algorithms can bias the calculation of risk adjusted operative mortality and significantly alter the results of surgeon specific profiles.

Can risk assessment ever distinguish the good from the bad surgeon? This is, of course, highly contentious but the answer is probably not. The opportunities for gaming are legion ${ }^{5}$ and even the use of VLAD plots ${ }^{6}$ does not prevent this activity. In New York City, where public scrutiny of individual cardiac surgeons' results has been intense, the risk assessment model is altered every year as the risk factors change and the knowledge of important variables grows. Does risk assessment facilitate informed consent? To some extent it does, but it needs to be tempered by the surgeon's own results (one of the lessons of Bristol) and the reality that our ability to assess the alternative risk of continued medical treatment is less developed. At a practical level, risk assessment allows the surgical scheduler to plan a sensible week's work around the staffing of the recovery and intensive care wards.

\section{MORTALITY AND MORBIDITY}

Mortality is relatively easy to measure but when the risk is low at $2-3 \%$, morbidity is actually of more interest and importance. Risk models for morbidity are significantly different. Risk factors associated with in-hospital death reflect coexisting disease specific variables whereas factors associated with length of stay include co-morbid illness. ${ }^{7}$ For example, a risk of death after bypass graft surgery (CABG) is associated with disease specific factors such as recent myocardial infarction and low ejection fraction, whereas the risk 
factors for increased length of stay and use of resources include co-morbidity such as peripheral vascular disease, chronic obstructive airways disease, and renal failure. Co-morbid conditions are important predictors of hospital costs because they often lead to prolonged hospital stay. Interestingly, the predictors of 3-4 year survival after coronary artery surgery are similar to those for morbidity and distinct from operative mortality. ${ }^{8}$ More studies that focus on morbidity as opposed to mortality are needed, but they should include an assessment of length of stay as a measure of resource utilisation, and quality of life as an indicator of patient satisfaction. Such outcome measures are particularly important for deciding how to use limited health budgets wisely. It has been estimated that as much as $40 \%$ of the yearly hospital costs for coronary artery surgery are consumed by $10-15 \%$ of the patients who have serious complications after operation. ${ }^{9}$

Waiting times for coronary surgery have recently assumed great political significance, but little has been done in the UK to develop a specific risk assessment scoring system based on urgency for patients on waiting lists. A report from Canada examined the hazard of waiting as well as the impact of waiting on surgical outcomes. ${ }^{10}$ They reported from a centre in Nova Scotia where a weekly peer review conference of cardiovascular experts prioritise each surgical case to one of four lists with the use of standardised criteria of coronary anatomy, stress test result, and symptoms. In their analysis of 2102 patients they concluded that death and priority upgrades tended to occur early in the queuing process, and prolonged waiting (more than four months) was not associated with worse surgical outcomes. A study from the Netherlands, ${ }^{11}$ where the median waiting time for routine coronary artery surgery was 3.5 months, came to similar conclusions to the
Canadians, in that complications occurred relatively early during the time on the waiting list, but it was not possible to predict these events with any accuracy.

In the future the prediction of mortality after coronary surgery may become more difficult. The current mortality figure for first time isolated coronary artery surgery of 3\% is low, the frequency of traditionally recognised risk factors is increasing, but the impact of these risk factors is decreasing. We should therefore turn our attention to morbidity.

\section{REFERENCES}

1 Mark DB. Implications of cost in treatment selection for patients with coronary disease. Ann Thorac Surg 1996;61:S12-15.

2 Grover FL, Shroyer AL, Hammermeister K, et al. A decade's experience with quality improvement in cardiac surgery using the Veterans Affairs and Society of Thoracic Surgeons national databases. Ann Thorac Surg 2001;234:464-72.

3 Petrou M, Roques F, Sharples LD, et al. The risk model of choice for coronary surgery in the UK. Heart 2003:89:98-9.

4 Ivanov J, Tu JV, Naylor CD. Ready-made, recalibrated, or remodeled? Issues in the use of risk indexes for assessing mortality after coronary artery bypass graft surgery. Circulation 1999;99:2098-104.

5 Burack JH, Impellizzeri P, Homel P, et al. Public reporting of surgical mortality: a survey of New York State cardiothoracic surgeons. Ann Thorac Surg 1999:68:1195-202.

6 Lovegrove J, Valencia O, Tyreasure T, et al. Monitoring the results of cardiac surgery by variable life-adjusted display. Lancet 1997; 350: 1128-30

7 Ferraris VA, Ferraris SP. Risk factors for postoperative morbidity. J Thorac Cardiovasc Surg 1996;111:731-6.

8 Gardner SXC, Grunwald GK, Rumsfield JS, et al. Risk factors for intermediate-term survival after coronary artery bypass grafting. Ann Thorac Surg 2001:72:2033-7.

9 lezzoni LI. Risk adjustment for medical effectiveness research: an overview of conceptual and methodological considerations. J Invest Med 1995;43: 136-43

10 Ray AA, Buth KJ, Sullivan JA, et al. Waiting for cardiac surgery: results of a risk-stratified queing process. Circulation 2001;104(suppl I):I-92-98.

11 Koomen EM, Hutten BA, Kelder JC, et al. Morbiodity and mortality in patients waiting for coronary artery bypass surgery. Eur J Cardiothorac Surg $2001 ; 19: 260-5$

\section{STAMPS IN CARDIOLOGY.}

\section{Heart research and ancient Greek medicine}

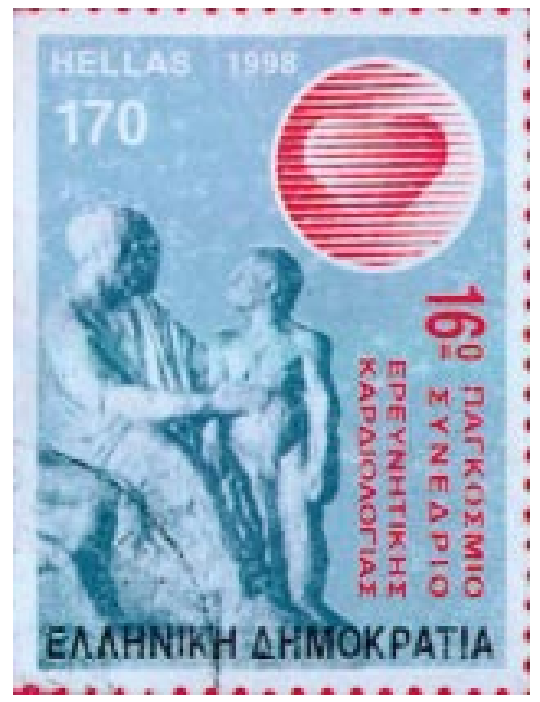

-his is the 170 drachmas Greek stamp issued in 1998 to commemorate the 16 th World Congress of the International Society for Heart Research, held the same year on the island of Rhodos in Greece.

The lower part of the stamp presents part of the Athenaean funerary stele of Jason (about 100 AD; nowadays in the British Museum). The relief shows the physician Jason of Acharnai seated and examining the young patient standing by palpation of the epigastrium.

Precordial palpation is an ancient and simple useful art of physical examination, continuing to be an integral part of cardiac evaluation. Careful clinical observations give important clues in diagnosis. Hippocratic medicine and in general ancient Greek medicine not only used careful observation, but interpreted their pathologic and physiologic meaning too. Hippocrates "started" medical research and developed medicine as a science and later on many other physicians in ancient Greece continued this process. In the diagnosis of heart diseases palpation is still essential and palpation itself has been the object of modern heart research.

T Tirilomis theodor.tirilomis@med.uni-goettingen.de 